\title{
p-Aminobenzamidine, an acrosin inhibitor, inhibits mouse sperm penetration of the zona pellucida but not the acrosome reaction
}

\author{
Lynn R. Fraser \\ Department of Human Biology, Chelsea College, Manresa Road, London SW3 6LX, U.K.
}

\begin{abstract}
Summary. The effect of $p$-aminobenzamidine (pAB), an inhibitor of mouse sperm acrosin, on mouse sperm capacitation, motility, acrosome loss and fertility in vitro was examined using zona-intact and zona-free eggs. With intact eggs, concentrations of $\mathrm{pAB}$ ranging from 0.1 to $1.0 \mathrm{~mm}$ in the sperm preincubation medium effectively inhibited fertilization (13-0\%, respectively), but these same suspensions $\left(10^{6}\right.$ cells $/ \mathrm{ml}$ ) showed high rates of fertilization with zona-free eggs $(100-95 \cdot 3 \%)$; with the lower concentration of $10^{5}$ cells $/ \mathrm{ml}$, fertilization rates of zona-free eggs decreased with increasing concentrations of pAB (100-55\%). Washing of treated samples gave fertilization rates similar to control samples $(87.1$ and $84.6 \%$, respectively), indicating that inhibition was reversible and that there had been no interference with the capacitation process. Whiplash motility was also observed in all samples, suggesting that the apparent inability to penetrate the zona might be due to an acrosomal defect. This was confirmed by electron microscopic examination of treated sperm samples. In high concentrations of $\mathrm{pAB}$, many cells had undergone the acrosome reaction, i.e. membrane vesiculation, but acrosomal matrix dispersal was inhibited. These results are consistent, therefore, with a role for the acrosomal enzyme acrosin in matrix dispersal, but not the acrosome reaction itself, and in penetration of the zona pellucida.
\end{abstract}

\section{Introduction}

Fertilization in mammals is a complex process which requires that spermatozoa first undergo capacitation, the transition from a non-fertilizing to a fertilizing gamete (Austin, 1951; Chang, 1951) which permits loss of the sperm acrosome, a prerequisite for normal sperm-egg interactions. The acrosome, a membrane-bound organelle in the sperm head containing an array of enzymes, undergoes an ordered series of alterations termed the acrosome reaction; the overlying sperm plasma membrane and the outer acrosomal membrane fuse to form vesicles (Bedford, 1970), thus permitting release or exposure of acrosomal contents which have been implicated in sperm penetration of the layers surrounding the egg (Morton, 1976).

Among the enzymes detected in the acrosome is the trypsin-like serine proteinase acrosin (Hartree, 1977) which has attracted much interest in recent years. It has been suggested that acrosin is probably involved in digestion of a path for the spermatozoon through the zona pellucida (Stambaugh \& Buckley, 1969). Various studies demonstrating the inhibition of fertilization in vivo and in vitro in the presence of trypsin and acrosin inhibitors (Stambaugh, Brackett \& Mastroianni, 1969; Miyamoto \& Chang, 1973; Wolf, 1977; Bhattacharyya, 
Goodpasture \& Zaneveld, 1979) and the ability of at least some acrosin preparations to remove zonae (Polakoski \& McRorie, 1973; Meizel \& Mukerji, 1976) have lent support to this hypothesis, although some reservations have been expressed (Hartree, 1977; Green, 1978b). Since the bulk of acrosomal contents are lost as a result of the acrosome reaction, it has been suggested that acrosin involved in zona penetration must be bound to the inner acrosomal membrane which forms the limiting membrane in the rostral part of an acrosome-free spermatozoon (Hartree, 1977); recently, histochemical localization of acrosin in guinea-pig spermatozoa undergoing the acrosome reaction has demonstrated this (Green \& Hockaday, 1978). A further role, that of initiation of the acrosome reaction itself, has been proposed by Meizel \& Lui (1976) and Lui \& Meizel (1979), but other studies have failed to confirm this (Green, 1978a; Shams-Borhan \& Harrison, 1981). Relatively little attention has been paid to sperm motility during fertilization in the presence of such inhibitors and motility is as important a factor in zona penetration as acrosome loss (Fraser, 1981). In an attempt to resolve some of the points of contention, the present study was designed to examine the effects of $p$-aminobenzamidine, a synthetic serine proteinase inhibitor which has been shown to inhibit mouse sperm acrosin (Bhattacharyya et al., 1979), on a wide range of characteristics associated with successful fertilization; e.g. capacitation, acrosome loss, motility and fertility at different sperm and inhibitor concentrations and using eggs in both their natural and denuded states.

\section{Materials and Methods}

\section{Media}

The medium used for all experiments was a modified Tyrode's solution (Fraser \& Drury, 1975) from which pyruvate and lactate had been omitted, leaving glucose as the only exogenous substrate; all media contained $4 \mathrm{mg}$ BSA (Armour; Eastbourne, Sussex) per ml. The serine proteinase inhibitor $p$-aminobenzamidine dihydrochloride (pAB) was obtained from Sigma, London. For incubation of sperm suspensions in the continuous presence of $\mathrm{pAB}$, a 5.0 or 1.0 mM solution in medium was prepared and diluted as needed. For introduction of pAB at the end of sperm preincubation, a stock of $20 \mathrm{mM}-\mathrm{pAB}$ was prepared, the $\mathrm{pH}$ adjusted with $\mathrm{NaOH}$ and aliquots then diluted to concentrations of 10 and $2 \mathrm{mM} ; 25 \mu$ of these stocks were added to 0.5 $\mathrm{ml}$ sperm suspensions to give final $\mathrm{pAB}$ concentrations of $1.0,0.5$ and $0.1 \mathrm{mM}$. All incubations were carried out at $37^{\circ} \mathrm{C}$ in $30 \mathrm{~mm}$ plastic dishes (Sterilin, Teddington, Middx.) overlaid with sterile (autoclaved) paraffin oil (Boots, Nottingham). The gas phase used throughout was $5 \%$ $\mathrm{CO}_{2}-5 \% \mathrm{O}_{2}-90 \% \mathrm{~N}_{2}$.

\section{In-vitro fertilization}

Mature TO females were induced to superovulate by i.p. injections of 7.5 i.u. PMSG (Gestyl: Organon, Morden, Surrey) and, approximately 48 h later, 5 i.u. hCG (Pregnyl: Organon); unfertilized eggs were recovered $14 \mathrm{~h}$ after hCG administration. In the following experiments, three different categories of eggs were used: intact, cumulus-free and zona-free. Intact eggs possessed the full array of cumulus cells and were released from oviducts directly into sperm suspensions. Cumulus-free eggs were prepared by releasing eggs into a solution of hyaluronidase (300 units/ml; bovine testes, Type I, Sigma, London) in culture medium for removal of cumulus cells; eggs were then briefly rinsed in enzyme-free medium before transfer to sperm suspensions. Zona-free eggs were prepared by first removing cumulus cells as above and then by brief treatment with $0.04 \%$ pronase (Koch-Light, Colnbrook, Bucks) which had been prepared and dialysed as described previously (Fraser, 1981). Eggs were rinsed twice in enzyme-free medium and transferred to sperm suspensions.

The cauda epididymides of 2 mature TO males were used for each experiment, with 
suspensions containing spermatozoa from both donors. A maximum of 4 suspensions $(0.5 \mathrm{ml}$ containing half the contents of 1 cauda from each male) could thus be prepared for one experiment. Suspensions were preincubated for $2 \mathrm{~h}$, diluted and eggs added.

Series $I$. Increasing concentrations of pAB $(0 \cdot 1,0.5,1.0$ and $5.0 \mathrm{~mm})$ were used for sperm preincubation and fertilization. Examination of suspensions at the end of preincubation suggested that overall motility was sometimes reduced in the higher concentrations of inhibitor, compared with the control group. To test the fertilizing ability of treated and untreated samples containing similar numbers of motile, and hence potentially fertilizing, spermatozoa, the samples were enriched for motile cells by eluting samples from short columns of Sephadex G-25 (Fraser \& Quinn, 1981) with the same medium used for preincubation. The sperm concentrations were then adjusted to approximately $10^{6}$ cells $/ \mathrm{ml}$ and a 10 -fold dilution of this, $10^{5} / \mathrm{ml}$, was also prepared. In this series, the filtered suspensions with $10^{6}$ cells $/ \mathrm{ml}$ were tested with intact and zona-free eggs, while the lower concentration of $10^{5} / \mathrm{ml}$ was tested only with zona-free eggs. In individual experiments, a sperm sample incubated in a single concentration of pAB was compared with one maintained in inhibitor-free, control medium. Three experiments were carried out for each concentration of $\mathrm{pAB}$.

Series II. Sperm suspensions were incubated for $2 \mathrm{~h}$ in inhibitor-free medium, then a concentrated preparation of inhibitor was added directly to the suspensions to bring the final concentration to $0.1,0.5$ and $1.0 \mathrm{mM}$. After a further $15 \mathrm{~min}$ incubation, the suspensions were diluted to $10^{6}$ cells $/ \mathrm{ml}$ in the appropriate inhibitor-containing medium and intact eggs were added. In each of 3 experiments, all concentrations of pAB were tested, along with control medium; suspensions were not filtered to enrich for motility because there was only a relatively short exposure to $\mathrm{pAB}$ before introduction of eggs.

Series $I I I$. The reversibility of pAB effects on fertilizing ability was examined by incubating sperm suspensions in $1.0 \mathrm{mM}$-pAB for $2 \mathrm{~h}$, washing an aliquot and re-suspending it in control medium. To wash, half the $\mathrm{pAB}$ sperm sample was placed in a conical centrifuge tube and 2 volumes of control medium were added; after gently mixing, the sample was centrifuged at $800 \mathrm{~g}$ for $4 \mathrm{~min}$. The supernatant was removed, the pellet resuspended in 3 volumes of control medium and centrifuged again. The pellet was gently resuspended to the original volume and the concentration then adjusted to $10^{6} \mathrm{cells} / \mathrm{ml}$. Fertilizing ability of this suspension was compared with the remaining unwashed $\mathrm{pAB}$-treated and control samples in 2 experiments.

Series IV. Sperm suspensions preincubated in $1.0 \mathrm{mM}$-pAB for $2 \mathrm{~h}$ were mixed with cumulus-free eggs for comparison with Series I experiments in which cumulus-intact eggs were used.

Series $V$. Zona-free eggs were princubated in $1.0 \mathrm{~mm}-\mathrm{pAB}$ for $30 \mathrm{~min}$, washed once and mixed with control sperm suspensions to determine whether the inhibitor had any effect on the eggs, rather than the spermatozoa. For each of these, 2 experiments were carried out.

\section{Assessment}

Fertility. After incubation with sperm suspension for approximately $65 \mathrm{~min}$, eggs were transferred to a fresh drop of medium under paraffin oil and at $75 \mathrm{~min}$ all groups were fixed by flooding the dishes with neutral buffered formalin (final concentration of $4 \%$ formaldehyde). Eggs were then transferred to a drop of $0.5 \%$ aceto-orcein on a microscope slide and a coverslip was added. Each egg was examined for signs of fertilization, i.e. resumption of meiosis II by the egg and a swelling sperm head. Fertilized eggs were further categorized as to both the stage of egg activation and the stage of sperm head decondensation. The proportions of eggs with nuclear development at terminal stages for the interval used, i.e. eggs at telophase-second polar body and sperm heads fully decondensed (Fraser, 1979, 1981), were calculated.

Motility. At the end of the incubation period samples were assessed for general motility and 
for the development of the characteristic whiplash motility pattern associated with fertilizing ability (Fraser, 1977, 1981).

Acrosome loss. All assessments of acrosomes were made on samples fixed for electron microscopy. Sperm suspensions were incubated for $2 \mathrm{~h}$ in the appropriate medium and centrifuged as described above; a few samples were filtered before centrifugation. The supernatant was removed and replaced with $2.5 \%$ glutaraldehyde in $0.1 \mathrm{M}$-cacodylate buffer, $\mathrm{pH} 7.4$; after a second centrifugation, fresh fixative was added. Following fixation, pellets were washed with buffer, post-fixed with $1 \%$ osmium tetroxide, dehydrated in graded alcohols and embedded in Epon. Sections were cut on a Reichert ultramicrotome and stained with uranyl acetate and lead citrate. Specimens were examined with a Philips $301 \mathrm{G}$ electron microscope. Spermatozoa in each sample were assessed for the presence or absence of an acrosome and the counts tabulated; at least 100 cells in each sample were counted and 2-3 separate preparations at each concentration of $\mathrm{pAB}$ were examined. Samples of spermatozoa preincubated in $\mathrm{pAB}$, washed and re-suspended in control medium were also examined after a further incubation of $15 \mathrm{~min}$, i.e. as used in Series III.

Statistical analysis. Results were analysed by the $\chi^{2}$ test; when necessary, Yates' correction for small numbers was used. A modification of this test, Cochran's test for combination of $2 \times 2$ contingency tables, was used for results obtained in Series II, in which values within a treatment showed a considerable range among experiments (Snedecor \& Cochran, 1967).

\section{Results}

\section{Series $I$}

High rates of fertilization were obtained with all sperm samples incubated in control, inhibitor-free medium and mixed with intact or zona-free eggs (Table 1). Most of the fertilized eggs were at advanced stages of egg activation and sperm head decondensation, indicating rapid and synchronous sperm penetration (Fraser, 1979, 1981). The observed incidence of polyspermy in zona-free eggs was high, especially with $10^{6}$ spermatozoa/ml.

Table 1. Inhibition of fertilization in vitro of mouse eggs by sperm suspensions preincubated for $2 \mathrm{~h}$ in increasing concentrations of $p$-aminobenzamidine in the same medium as used for fertilization

\begin{tabular}{|c|c|c|c|c|c|c|}
\hline Medium & $\begin{array}{l}\text { Sperm } \\
\text { conc. } / \mathrm{ml}\end{array}$ & \pm Zona & $\begin{array}{c}\text { Eggs } \\
\text { fertilized (\%) }\end{array}$ & $\begin{array}{c}\text { Telophase-polar } \\
\text { body } 2 \text { egg stage, } \\
\%\end{array}$ & $\begin{array}{l}\text { Sperm head } \\
\text { stage } 3 \dagger, \%\end{array}$ & $\begin{array}{l}\text { Polyspermic } \\
\text { eggs, \% }\end{array}$ \\
\hline Control & $\begin{array}{l}10^{6} \\
10^{6} \\
10^{5}\end{array}$ & $\frac{+}{-}$ & $\begin{array}{c}55 / 61 \quad(90 \cdot 2) \\
118 / 118(100) \\
104 / 104(100)\end{array}$ & $\begin{array}{l}94 \cdot 5 \\
99 \cdot 2 \\
100\end{array}$ & $\begin{array}{l}92 \cdot 7 \\
100 \\
100\end{array}$ & $\begin{array}{l}\text { n.d. } \neq \\
83 \cdot 1 \\
37 \cdot 5\end{array}$ \\
\hline $0.1 \mathrm{~mm}-\mathrm{pAB}$ & $\begin{array}{l}10^{6} \\
10^{6} \\
10^{5}\end{array}$ & \pm & $\begin{aligned} 8 / 60 & (13 \cdot 3)^{*} \\
49 / 49 & (100) \\
38 / 38 & (100)\end{aligned}$ & $\begin{array}{l}75 \cdot 0 \\
100 \\
100\end{array}$ & $\begin{array}{l}75 \cdot 0 \\
100 \\
100\end{array}$ & $\begin{array}{l}\text { n.d. } \neq \\
73 \cdot 5 \\
36 \cdot 8\end{array}$ \\
\hline $0.5 \mathrm{~mm}-\mathrm{pAB}$ & $\begin{array}{l}10^{6} \\
10^{6} \\
10^{5}\end{array}$ & $\frac{+}{-}$ & $\begin{aligned} 1 / 63 & (1 \cdot 6)^{*} \\
39 / 39 & (100) \\
25 / 30 & (83 \cdot 3)^{*}\end{aligned}$ & $\begin{array}{c}0 \\
100 \\
100\end{array}$ & $\begin{array}{c}0 \\
100 \\
100\end{array}$ & $\begin{array}{l}\text { n.d. } \\
38 \cdot 5^{*} \\
8 \cdot 0^{*}\end{array}$ \\
\hline $1.0 \mathrm{~mm}-\mathrm{pAB}$ & $\begin{array}{l}10^{6} \\
10^{6} \\
10^{5}\end{array}$ & $\begin{array}{l}+ \\
-\end{array}$ & $\begin{aligned} 0 / 93 & (0) \\
61 / 64 & (95 \cdot 3)^{*} \\
22 / 40 & (55 \cdot 0)^{*}\end{aligned}$ & $\begin{array}{c}0 \\
85 \cdot 2 \\
72 \cdot 7\end{array}$ & $\begin{array}{c}0 \\
91.8 \\
68.2\end{array}$ & $\begin{array}{c}0 \\
18 \cdot 0^{*} \\
0^{*}\end{array}$ \\
\hline
\end{tabular}

$\dagger$ Fully decondensed.

$\ddagger$ Not determined.

* $P<0.001$, compared with control group. 
With intact eggs, fertilization rates in the presence of $0.1,0.5$ and $1.0 \mathrm{mM}-\mathrm{pAB}$ ranged from 13.3 to $0 \%$, respectively; there was no detectable inhibition of cumulus-cell dispersal at any concentration of $\mathrm{pAB}$. Considerably higher rates were obtained with zona-free eggs. Using a sperm concentration of $10^{6} / \mathrm{ml}$, high fertility was obtained with all 3 concentrations of pAB (100 to $95 \cdot 3 \%$ ), although the incidence of polyspermy was significantly reduced compared with that in controls $(P<0.001)$ when the inhibitor concentration exceeded $0.1 \mathrm{~mm}$. With the lower sperm concentration of $10^{5} / \mathrm{ml}$, rates of fertilization were clearly affected by inhibitor, with the figures ranging from $100 \%$ with $0.1 \mathrm{mM}-\mathrm{pAB}$ to $55.0 \%$ with $1.0 \mathrm{mM}-\mathrm{pAB}$; again, the incidence of polyspermy decreased as pAB concentration increased. Furthermore, in zona-free eggs fertilized in the presence of $1.0 \mathrm{mM}-\mathrm{pAB}$, the stages of nuclear development observed were frequently less advanced than in the other groups. An analysis of the degree of polyspermy in zona-free eggs indicated very little difference between the control and $0.1 \mathrm{~mm}$-pAB groups (Table 2). With 0.5 and $1.0 \mathrm{~mm}-\mathrm{pAB}$, however, almost all polyspermic eggs were dispermic, with relatively few trispermic ones.

Table 2. Degree of polyspermy in zona-free mouse eggs fertilized in vitro in the presence of $p$-aminobenzamidine

\begin{tabular}{lcccc}
\hline \multirow{2}{*}{ Medium } & $\begin{array}{c}\text { Sperm } \\
\text { conc. }\end{array}$ & $\begin{array}{c}\text { Monospermic, } \\
\%\end{array}$ & $\begin{array}{c}\text { Dispermic, } \\
\%\end{array}$ & $\begin{array}{c}\text { Trispermic }+ \text {, } \\
\%\end{array}$ \\
\hline Control & $10^{6} / \mathrm{ml}$ & 17.0 & 42.4 & 40.6 \\
& $10^{5} / \mathrm{ml}$ & 61.5 & 31.2 & 7.3 \\
$0.1 \mathrm{mM}-\mathrm{pAB} *$ & $10^{6} / \mathrm{ml}$ & 16.3 & 59.2 & 24.5 \\
& $10^{5} / \mathrm{ml}$ & 63.2 & 28.9 & 7.9 \\
$0.5 \mathrm{mM}^{*} \mathrm{pAB}^{*}$ & $10^{6} / \mathrm{ml}$ & 59.0 & 33.3 & 7.7 \\
& $10^{5} / \mathrm{ml}$ & 92.0 & 8.0 & 0 \\
$1.0 \mathrm{mM}-\mathrm{pAB}^{*}$ & $10^{6} / \mathrm{ml}$ & 79.7 & 20.3 & 0 \\
& $10^{5} / \mathrm{ml}$ & 100 & 0 & 0 \\
\hline
\end{tabular}

* Sperm suspensions were preincubated for $2 \mathrm{~h}$ in medium containing $\mathrm{pAB}$ and then diluted to $10^{6}$ and $10^{5}$ cells $/ \mathrm{ml}$.

Series $I I$

When $\mathrm{pAB}$ was added to sperm suspensions $15 \mathrm{~min}$ before mixing with intact eggs, there was a range of mean fertilization rates (Table 3 ). The range among individual experiments was large, differing in this respect from the control group. In general, the higher the concentration of $\mathrm{pAB}$ the lower the level of fertilization observed. Most of these fertilized egss were at earlier stages of nuclear development than those in the control group

Table 3. Inhibition of fertilization in vitro of mouse eggs in the presence of $p$-aminobenzamidine

\begin{tabular}{|c|c|c|c|c|}
\hline \multirow[b]{2}{*}{ Medium } & \multicolumn{2}{|c|}{ Eggs fertilized } & \multirow{2}{*}{$\begin{array}{c}\text { Telophase- } \\
\text { polar body } 2 \\
\text { egg stage, } \\
\%\end{array}$} & \multirow{2}{*}{$\begin{array}{c}\text { Sperm head stage } \\
3, \%\end{array}$} \\
\hline & No. & $\%$ (range) & & \\
\hline Control & $63 / 74$ & $\begin{array}{c}85 \cdot 1 \\
(81 \cdot 8-89 \cdot 5)\end{array}$ & 88.9 & $85 \cdot 7$ \\
\hline $0.1 \mathrm{~mm}-\mathrm{pAB} \dagger$ & $28 / 63$ & $\begin{array}{c}44 \cdot 4^{*} \\
(19 \cdot 1-70 \cdot 4)\end{array}$ & $32 \cdot 1$ & $14 \cdot 3$ \\
\hline $0.5 \mathrm{~mm}-\mathrm{pAB} \dagger$ & $13 / 73$ & $\begin{array}{l}17.8^{* *} \\
(0-57 \cdot 1)\end{array}$ & 53.8 & $46 \cdot 2$ \\
\hline $1.0 \mathrm{mM}-\mathrm{pAB} \dagger$ & $10 / 82$ & $\begin{array}{c}12 \cdot 2^{* * *} \\
(0-42 \cdot 1)\end{array}$ & $40 \cdot 0$ & $40 \cdot 0$ \\
\hline
\end{tabular}

$\dagger$ Sperm suspensions were incubated for $2 \mathrm{~h}$ in control medium, with $\mathrm{pAB}$ introduced $15 \mathrm{~min}$ before addition of eggs.

Compared with control group, ${ }^{*} P<0.025 ;{ }^{* *} P<0.01 ;{ }^{* * *} P<0.001$. 


\section{Series III}

When sperm samples preincubated for $2 \mathrm{~h}$ in $1.0 \mathrm{~mm}-\mathrm{pAB}$ were washed and resuspended in inhibitor-free medium, rates of fertilization and stages of nuclear development did not differ significantly from those obtained with control samples (Table 4). Unwashed pAB samples were unable to fertilize intact eggs.

Table 4. Reversibility of $p$-aminobenzamidine-induced inhibition of mouse sperm fertilizing ability in vitro.

\begin{tabular}{lccc}
\hline Medium & $\begin{array}{c}\text { Eggs fertilized } \\
(\%)\end{array}$ & $\begin{array}{c}\text { Telophase-polar } \\
\text { body 2 egg stage, } \%\end{array}$ & $\begin{array}{c}\text { Sperm head stage } \\
3, \%\end{array}$ \\
\hline Control & $\begin{array}{c}22 / 26 \\
(84 \cdot 6)\end{array}$ & 100 & 100 \\
1.0 mM-pAB & $\begin{array}{c}0 / 28^{* * *} \\
(0)\end{array}$ & 0 & 0 \\
$\begin{array}{c}27 / 31 \\
\text { 1.0 mM-pAB, } \\
\text { washed } \dagger\end{array}$ & $(87.1)$ & 96.3 & 96.3 \\
\hline
\end{tabular}

† Sperm suspensions were incubated for $2 \mathrm{~h}$ in $\mathrm{pAB}$, washed and re-suspended in control medium.

${ }^{* * *} P<0.001$, compared with control group.

\section{Series IV and $V$}

When sperm samples preincubated in $1.0 \mathrm{mM}-\mathrm{pAB}$ were mixed with cumulus-free eggs, no fertilization was obtained $(0 / 27$; results not tabulated). The preincubation of zona-free eggs in $1.0 \mathrm{~mm}$-pAB reduced neither the rate of fertilization (100\%) nor the incidence of polyspermy $(81.8 \%)$, compared with control samples (results not tabulated). Although the high concentration of 5.0 mM-pAB was tested initially, spermatozoa were immotile after a $2 \mathrm{~h}$ preincubation and this concentration was not considered further.

Table 5. Electron microscopic assessment of acrosome loss in mouse spermatozoa incubated for $2 \mathrm{~h}$ in increasing concentrations of $p$-aminobenzamidine

\begin{tabular}{|c|c|c|c|c|}
\hline \multirow[b]{2}{*}{ Medium } & \multicolumn{3}{|c|}{ Appearance of acrosome, $\%$} & \multirow{2}{*}{$\begin{array}{c}\text { Total } \\
\text { acrosome breakdown, \% } \\
\text { (mean } \pm \text { s.e.m.) }\end{array}$} \\
\hline & Present & Absent & Vesicles + matrix & \\
\hline Control & $57 \cdot 9$ & $40 \cdot 0$ & $2 \cdot 1$ & $42 \cdot 1 \pm 1 \cdot 9$ \\
\hline $0.1 \mathrm{~mm}-\mathrm{pAB}$ & 59.4 & $29 \cdot 4^{* *}$ & $11 \cdot 3^{* * *}$ & $40 \cdot 7 \pm 2 \cdot 2$ \\
\hline $0.5 \mathrm{mM}-\mathrm{pAB}$ & $54 \cdot 8$ & $7 \cdot 7^{* * *}$ & $37 \cdot 6^{* * *}$ & $45 \cdot 3 \pm 2 \cdot 0$ \\
\hline $1.0 \mathrm{mM}-\mathrm{pAB}$ & $53 \cdot 5$ & $2 \cdot 5^{* * *}$ & $44 \cdot 1^{* * *}$ & $46.5 \pm 1.9$ \\
\hline $\begin{array}{c}1.0 \text { mM-pAB, } \\
\text { washed } \dagger\end{array}$ & $44 \cdot 7$ & $13 \cdot 2^{* * *}$ & $42 \cdot 0^{* * *}$ & $55 \cdot 3 \pm 1 \cdot 1$ \\
\hline
\end{tabular}

$\dagger$ Treated as described in the text and incubated a further 15 min before fixation. Compared with control group, ${ }^{* *} P<0.01{ }^{* * *} P<0.001$.

\section{PLATE 1}

Fig. 1. Acrosome-free mouse spermatozoon; sample fixed after $2 \mathrm{~h}$ incubation in inhibitor-free medium. $\times 80000$.

Fig. 2. Spermatozoon which has undergone the acrosome reaction; sample fixed after $2 \mathrm{~h}$ incubation in inhibitor-free medium. $\times 80000$.

Fig. 3. Spermatozoon which has undergone the acrosome reaction and retained much of the acrosomal matrix; sample fixed after $2 \mathrm{~h}$ incubation in $0.5 \mathrm{~mm}-\mathrm{pAB} . \times 60000$.

Fig. 4. Spermatozoon similar to that in Fig. 3 but fixed after $2 \mathrm{~h}$ incubation in $1.0 \mathrm{~mm}-\mathrm{pAB}$. $\times 60000$. 
PLATE 1
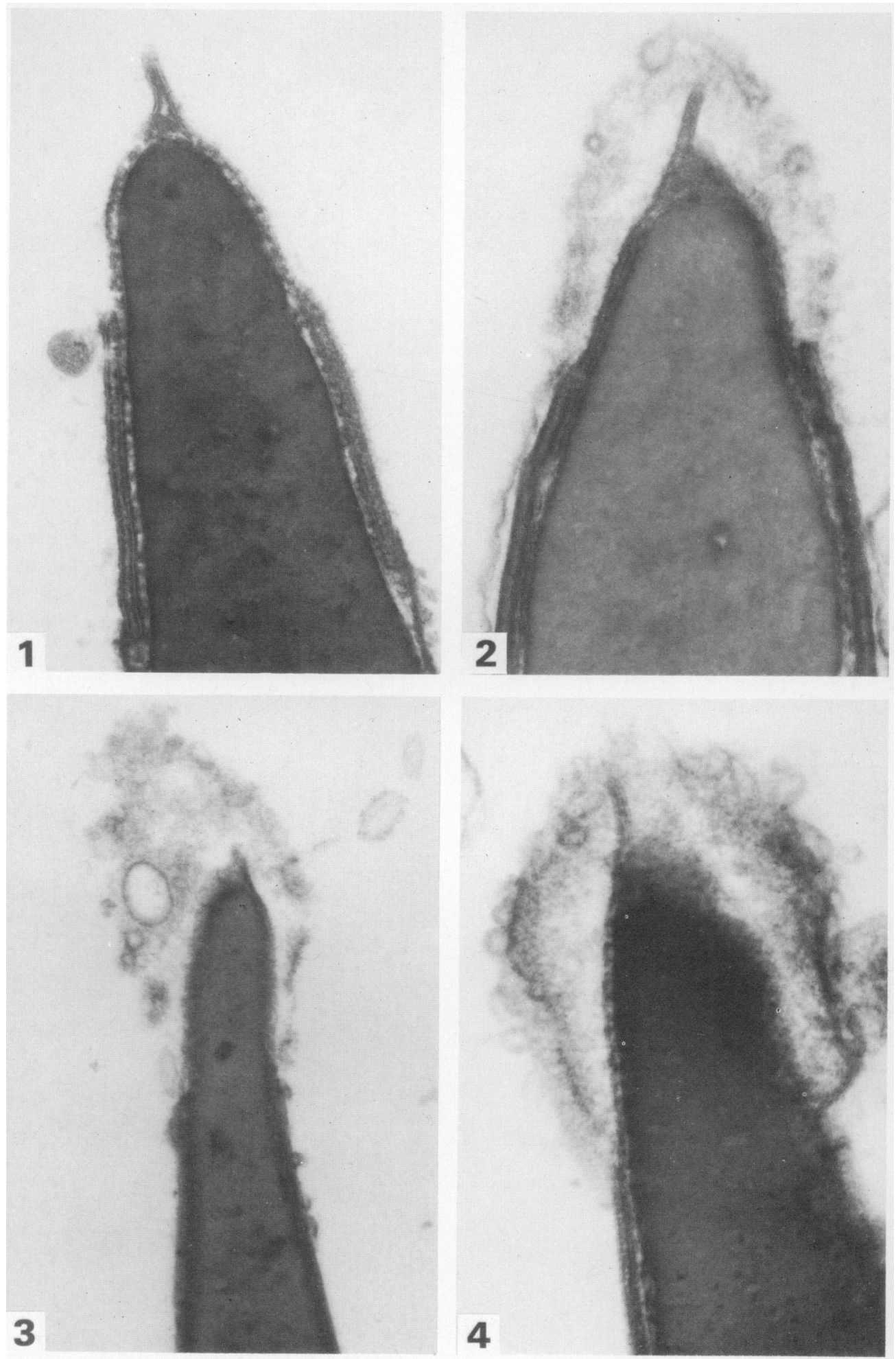

(Facing p. 190) 
Motility

General motility was somewhat lower in the higher concentrations of inhibitor, although very good motility was observed in all samples after gel filtration ( $\sim 90 \%$ motile). The majority of motile spermatozoa in control as well as all inhibitor-containing media exhibited whiplash motility (Fraser, 1977).

\section{Acrosome loss}

Electron microscopic examination of samples incubated in the absence of inhibitor revealed that most cells either had an intact acrosome or were totally lacking the organelle, leaving the inner acrosomal membrane exposed (Pl. 1, Fig. 1); very few cells were seen with membrane vesiculation and matrix dispersal (Pl. 1, Fig. 2). In contrast, a high proportion of spermatozoa with acrosomal vesicles and undispersed matrix material was noted in the $\mathrm{pAB}$-treated samples. In the continuous presence of $0.1 \mathrm{mM}-\mathrm{pAB}$, the overall profile of cells was similar to that of the control group, but more cells had attached vesicles and matrix (Table 5). In the presence of 0.5 and $1.0 \mathrm{mM}-\mathrm{pAB}$ many more spermatozoa had vesicles and matrix still present (Pl. 1, Figs 3 and 4 ), with the amount of matrix material frequently greater in the $1.0 \mathrm{~mm}$ samples. The vesiculation process observed in the presence of the inhibitor was frequently less regular than that observed in control medium and considerable variation was noted among cells; in all instances, however, acrosome integrity was disrupted. The total proportion of spermatozoa displaying acrosomal breakdown was similar in control and treated groups, ranging from $42 \cdot 1$ to $46.5 \%$. Only a few samples were filtered before fixation because of insufficient yield for preparative procedures, but the distribution of cells with intact and disrupted acrosomes was similar to that observed in unfiltered samples and all results have been combined. In the samples incubated in $1.0 \mathrm{mM}-\mathrm{pAB}$ and then washed, the overall incidence of acrosome reaction had increased because of the longer total incubation period. Although the majority of these cells had vesicles, a significantly higher $(P<0.001)$ proportion of cells was totally acrosome-free, compared with unwashed $\mathrm{pAB}$ samples. This category was still much smaller than the corresponding one in the control samples, however.

\section{Discussion}

Results from the present study demonstrate that fertilization in vitro by mouse spermatozoa is inhibited in the presence of the acrosin inhibitor, $p$-aminobenzamidine (pAB). When the sperm suspensions were preincubated for $2 \mathrm{~h}$ in the presence of $\mathrm{pAB}$, fertilization of zona-intact eggs was almost totally inhibited with all concentrations tested $(0 \cdot 1-1.0 \mathrm{~mm})$. Cumulus cell dispersal in the presence of these sperm suspensions was normal and the removal of cumulus cells with hyaluronidase before gamete mixing did not affect the observed inhibition, suggesting that the spermatozoa were unable to penetrate the zona. In marked contrast, when zonae were removed before mixing with spermatozoa, high rates of fertilization were obtained in the presence of all concentrations of $\mathrm{pAB}$ when the sperm concentration was $10^{6}$ cells $/ \mathrm{ml}$, although at $10^{5}$ cells $/ \mathrm{ml}$ significantly lower rates were obtained with 0.5 and $1.0 \mathrm{~mm}$-pAB. No effect of pAB on motility was detected in the samples used for fertilization. Suspensions were enriched for motile gametes (Fraser \& Quinn, 1981) before mixing with eggs and whiplash motility, required for penetration of the zona (Fraser, 1981), was observed in the majority of cells at all concentrations of pAB used. This is consistent with the study of Lui \& Meizel (1979) who detected no effect on similar motility in hamster spermatozoa treated with acrosin inhibitors. The failure to fertilize zona-intact eggs could not be ascribed to inadequate or inappropriate motility and the spermatozoa were clearly able to fuse with zona-free eggs. Therefore, pAB effectively inhibited sperm penetration through the zona pellucida by a mechanism other than interference with 
motility. Since pAB has been shown to inhibit mouse sperm acrosin (Bhattacharyya et al., 1979) which is located in the acrosome (Green \& Hockaday, 1978), these results are consistent with acrosin involvement in zona penetration.

The inhibition obtained with $\mathrm{pAB}$ was reversible since washing of treated spermatozoa before introduction of eggs resulted in fertilization rates similar to those observed in the control group. The majority of eggs in both groups had reached terminal stages of nuclear development, demonstrating that sperm penetration was both rapid and synchronous. This is characteristic of fully capacitated mouse sperm suspensions (Fraser, 1979, 1981; Fraser \& Quinn, 1981) and indicated that, although $\mathrm{pAB}$ inhibited fertilization, it did not inhibit capacitation; once the inhibitor was removed, gametes were immediately and fully functional.

While the inhibitor had no apparent effect on capacitation and development of whiplash motility, electron microscopic examination of spermatozoa incubated for $2 \mathrm{~h}$ in pAB revealed specific differences between control and inhibitor-treated samples. In the absence of inhibitor, approximately $40 \%$ of cells had lost the acrosome, leaving the inner acrosomal membrane exposed. Very few spermatozoa were actually observed in the process of vesiculation and little acrosomal matrix was present in these cells, suggesting that acrosome loss occurs rapidly in individual cells. In the pAB-treated samples, the striking difference noted was the presence of cells in which membrane vesiculation and retention of a large proportion of the electron-dense acrosomal matrix material were evident, a state not observed in the control samples. In $0 \cdot 1$ mM-pAB, most of the spermatozoa in which the acrosome reaction had occurred were totally acrosome-free and, as such, were indistinguishable from cells in the control samples; a small proportion of cells displayed the vesiculation and matrix retention state. In the presence of 0.5 and $1.0 \mathrm{mM}-\mathrm{pAB}$, most of the cells had either an intact acrosome or vesicles plus matrix, with few lacking acrosomal components. Subjectively, the amount of matrix retained was frequently higher in the presence of $1.0 \mathrm{mM}-\mathrm{pAB}$, but there was variation from cell to cell and quantitation would have been difficult. The appearance of the disrupted membrane components also varied, in some cells resembling the vesiculation observed in control samples and in others appearing to represent a less orderly process. However, the total proportion of cells that had undergone the acrosome vesiculation was similar in all samples whether or not $\mathrm{pAB}$ was present. The fact that many cells in $0.1 \mathrm{~mm}$ samples were able to undergo a morphologically normal acrosome reaction yet were unable to penetrate the zona lends further support to a localization of acrosin on the inner acrosomal membrane in cells which have undergone complete acrosome loss.

These ultrastructural observations indicate that in the presence of a compound which has been shown to inhibit mouse sperm acrosin, acrosomal membranes do not remain intact; thus acrosin would not appear to function in initiation of the mouse sperm acrosome reaction, as proposed by Meizel \& Lui (1976) and Lui \& Meizel (1979) for hamster spermatozoa. On the other hand, these results are consistent with the proposal made by Green $(1978 \mathrm{a}, \mathrm{b})$ and Shams-Borhan \& Harrison (1981) that sperm acrosin plays a role in acrosomal matrix dispersal. In these latter studies which used guinea-pig and ram spermatozoa, respectively, the rate of hyaluronidase release into the medium was unaffected by the presence of acrosin inhibitors, suggesting that hyaluronidase could escape readily from the disrupted acrosomes. Such a release had been inferred in the present study because cumulus cell dispersal was not affected by inhibitor. In the intact acrosome, most of the acrosin is present in an inactive zymogen form known as proacrosin (Meizel \& Mukerji, 1976; Green, 1978a; Bhattacharyya et al., 1979; Shams-Borhan \& Harrison, 1981) and around the time of the acrosome reaction, proacrosin undergoes autoactivation by acrosin cleavage of the zymogen; this results in the appearance of active enzyme (Green, 1978a). The retention of acrosomal matrix in the presence of acrosin inhibitors has suggested, therefore, that much of this matrix consists of aggregated proacrosin unable to undergo normal activation (Shams-Borhan \& Harrison, 1981). Such retention in effective concentrations of various small synthetic acrosin inhibitors would maintain the basic shape of the intact acrosome when assessed with the light microscope and this may account for some of the discrepancies among the studies cited. 
When pAB was introduced just before addition of eggs, inhibition was observed in a concentration-dependent manner but the degree of inhibition observed with a single concentration varied among experiments. These results lend support to the view that acrosome loss by the fertilizing spermatozoon occurs in the immediate vicinity of the egg (Meizel, 1978), i.e. that the fertilizing cells are not those that have already lost the acrosome before reaching the egg but rather those that do so very close to the egg. At the time pAB was added, approximately $34-40 \%$ of the spermatozoa would have been acrosome-free (present study; Fraser, 1977, 1981) and any acrosin bound to the inner acrosomal membrane would have been immediately accessible to the inhibitor, yet complete inhibition was not obtained consistently even with 1.0 mM-pAB. While it has been reported that bound acrosin, compared with soluble acrosin, is inhibited less readily by some compounds, this is apparently not true for pAB (Hartree, 1977) and hence any differences between bound and soluble enzyme would not appear to be involved. Effective inhibition of acrosin, proacrosin or proacrosin activation within the acrosome of a capacitated spermatozoon may require longer than the $15 \mathrm{~min}$ interval allowed before introduction of eggs, thus permitting higher fertilization rates than observed in the continuous presence of $\mathrm{pAB}$. On the other hand, it was evident that sperm penetration was retarded in the presence of $\mathrm{pAB}$, and this would be consistent with a slower dispersal of acrosomal matrix to expose the inner acrosomal membrane. Finally, pAB-treated and washed samples were highly fertile, yet morphologically there was only a small proportion of acrosome-free cells present. Comparison with unwashed samples suggests that most of the these would have lost the acrosome after pAB removal. If only cells which had lost the acrosome before addition of eggs were capable of fertilization, then much lower rates would be predicted on the basis of so few acrosome-free cells (Fraser, 1981). The fact that fertilization rates were high with no delay in sperm penetration would suggest that many competent cells were present and able to function, i.e. undergo normal acrosome loss, when supplied with the appropriate stimulus, presumably from the eggs.

Wolf (1977) has suggested that sperm acrosin might play a role in sperm-egg fusion, based on experiments using zona-free mouse eggs and sperm suspensions treated with $\mathrm{pAB}$ at concentrations ranging from 0.75 to $3.0 \mathrm{~mm}$. From the results presented here, this inhibition may well reflect a reduced ability of spermatozoa with the bulk of acrosomal material still in place to obtain the correct alignment for fusion, rather than a role for the enzyme itself in this process. In the present study there was a direct correlation between the proportion of zona-free eggs fertilized and the morphology of sperm suspensions in the presence of pAB. In $0.1 \mathrm{~mm}-\mathrm{pAB}$ many cells were acrosome-free and, although their fertility with zona-intact eggs was extremely low, it was indistinguishable from control samples with zona-free eggs; furthermore, the incidence of polyspermy did not differ significantly between the two groups of spermatozoa. Since the majority of spermatozoa which fuse with these eggs do so synchronously, the incidence of polyspermy is an indicator of the relative quality of the sperm suspensions (Fraser, 1981). In higher concentrations of $\mathrm{pAB}$, both fertility and polyspermy with zona-free eggs were affected, but these were the samples in which much of the acrosomal material was retained. The observed inhibition may represent steric rather than enzymic difficulties. From light microscopic assessment of sperm head decondensation, it is evident that the visible line of fusion between spermatozoon and egg proceeds from the posterior to the anterior region of the head, generally along the convex portion; this process would be much more difficult with acrosomal contents still in place.

In conclusion, the present study has demonstrated that, in the presence of a compound known to inhibit acrosin, mouse spermatozoa are unable to penetrate the zona pellucida of intact eggs but are able to fuse with zona-free eggs. The inhibitor effect in mediated via the acrosome rather than capacitation or motility. The acrosome reaction, i.e. membrane vesiculation, occurs in the presence of inhibitor but dispersal of the matrix is inhibited in a concentration-dependent manner. These results are therefore consistent with acrosin involvement both in acrosomal matrix dispersal, possibly by activation of proacrosin, and in sperm $_{1}$ penetration of $_{4}$ the $_{2}$ zona $_{1: 53: 07 \mathrm{PM}}$ 
pellucida, by acrosin bound to the inner acrosomal membrane. The possible use of acrosin inhibitors such as $\mathrm{pAB}$ as potential contraceptives has been examined (e.g. Zaneveld, Robertson \& Williams, 1970; Joyce, Freund \& Peterson, 1979; Zaneveld, Beyler, Kim \& Bhattacharyya, 1979). Although there appear to be some possible difficulties with the compounds used to date (e.g. toxicity), this approach has much to recommend it theoretically and should be pursued further.

I thank Mrs Chris LeBlond for preparing the samples for electron microscopy and Dr Shams-Borhan and Dr Harrison for a pre-publication copy of their manuscript. This study was supported in part by a grant from the Marie Stopes Research Fund.

\section{References}

Austin, C.R. (1951) Observations on the penetration of sperm into the mammalian egg. Aust. J. Sci. Res. B 4, 581-596.

Bedford, J.M. (1970) Sperm capacitation and fertilization in mammals. Biol. Reprod., Suppl. 2, 128-158.

Bhattacharyya, A.K., Goodpasture, J.C. \& Zaneveld, L.J.D. (1979) Acrosin of mouse spermatozoa. Am.J. Physiol. 237, E40-44.

Chang, M.C. (1951) Fertilizing capacity of spermatozoa deposited into the fallopian tubes. Nature, Lond. 168, 697-698.

Fraser, L.R. (1977) Motility patterns in mouse spermatozoa before and after capacitation. J. exp. Zool. 202, 439-444.

Fraser, L.R. (1979) Rate of fertilization in vitro and subsequent nuclear development as a function of the post-ovulatory age of the mouse egg. J. Reprod. Fert. $55,153-160$.

Fraser, L.R. (1981) Dibutyryl cyclic AMP decreases capacitation time in vitro in mouse spermatozoa. $J$. Reprod. Fert. 62, 63-72.

Fraser, L.R. \& Drury, L.M. (1975) The relationship between sperm concentration and fertilization in vitro of mouse eggs. Biol. Reprod. 13, 513-518.

Fraser, L.R. \& Quinn, P.J. (1981) A glycolytic product is obligatory for initiation of the sperm acrosome reaction and whiplash motility required for fertilization in the mouse. J. Reprod. Fert. 61, 25-35.

Green, D.P.L. (1978a) The activation of proteolysis in the acrosome reaction of guinea-pig sperm. J. Cell Sci. 32, 177-184.

Green, D.P.L. (1978b) The mechanism of the acrosome reaction. In Development in Mammals, Vol. 3, pp. 65-81. Ed. M. H. Johnson. Elsevier-North Holland, Amsterdam.

Green, D.P.L. \& Hockaday, A.R. (1978) The histochemical localization of acrosin in guinea-pig sperm after the acrosome reaction. J. Cell Sci. 32, 177-184.

Hartree, E.F. (1977) Spermatozoa, eggs and proteinases. Biochem. Soc. Trans. 5, 373-394.

Joyce, C., Freund, M. \& Peterson, R. (1979) Contraceptive effects of acrosin and hyaluronidase inhibitors in rabbit. Contraception 19, 95-106.

Lui, C.W. \& Meizel, S. (1979) Further evidence in support of a role for hamster sperm hydrolytic enzymes in the acrosome reaction. J. exp. Zool. 207, $173-186$.

Meizel, S. (1978) The mammalian sperm acrosome reaction, a biochemical approach. In Development in Mammals, Vol. 3, pp. 1-64. Ed. M. H. Johnson. Elsevier-North Holland, Amsterdam.

Meizel, S. \& Lui, C.W. (1976) Evidence for the role of a trypsin-like enzyme in the hamster sperm acrosome reaction. J. exp. Zool. 195, 137-144.

Meizel, S. \& Mukerji, S.K. (1976) Biochemical studies of proacrosin and acrosin from hamster cauda epididymal spermatozoa. Biol. Reprod. 14, 444-450.

Miyamoto, H. \& Chang, M.C. (1973) Effect of protease inhibitors on the fertilizing capacity of hamster spermatozoa. Biol. Reprod. 9, 533-537.

Morton, D.B. (1976) Lysosomal enzymes in mammalian spermatozoa. In Lysosomes in Biology and Pathology, Vol. 5, pp. 203-255. Eds J. T. Dingle \& R. T. Dean. Elsevier-North Holland, Amsterdam.

Polakoski, K.L. \& McRorie, R.A. (1973) Boar acrosin. II. Classification, inhibition and specificity studies of a proteinase from sperm acrosomes. J. biol. Chem. 248, 8183-8188.

Shams-Borhan, G. \& Harrison, R.A.P. (1981) Production, characterization and use of ionophoreinduced, calcium-dependent acrosome reaction in ram spermatozoa. Gamete Res. 4, 407-432.

Snedecor, G. \& Cochran, W. (1967) Statistical Methods, 6th edn. Iowa State University Press, Ames.

Stambaugh, R. \& Buckley, J. (1969) Identification and subcellular localization of the enzymes effecting penetration of the zona pellucida by rabbit spermatozoa. J. Reprod. Fert. 19, 423-432.

Stambaugh, R., Brackett, B.G. \& Mastroianni, L. (1969) Inhibition of in vitro fertilization of rabbit ova by trypsin inhibitors. Biol. Reprod. 1, 223-227.

Wolf, D.P. (1977) Involvement of a trypsin-like activity in sperm penetration of zona-free mouse ova. $J$. exp. Zool. 199, 149-156.

Zaneveld, L.J.D., Robertson, R.T. \& Williams, W.L. (1970) Synthetic enzyme inhibitors as antifertility agents. FEBS Letters 11, 345-347.

Zaneveld, L.J.D., Beyler, S.A., Kim, D.S. \& Bhattacharyya, A.K. (1979) Acrosin inhibitors as vaginal contraceptives in the primate and their acute toxicity. Biol. Reprod. 20, 1045-1054. 